\title{
IMPACTOS DO ENSINO, PESQUISA E EXTENSÃO UNIVERSITÁRIA: INSTRUMENTO DE TRANSFORMAÇÃO SOCIOAMBIENTAL
}

\author{
Ana Lucia Berno Bonassina ${ }^{1}$ \\ Katia Naomi Kuroshima²
}

Resumo: Este estudo, teórico-analítico, propõe uma reflexão sobre como a ampliação da conscientização ambiental pode ser aprimorada nas escolas a partir das práticas extensionistas contínuas. Um questionário objetivo, de escala Likert, foi aplicado em seis escolas de Itajaí (SC), contemplando 62 estudantes participantes das atividades do Projeto de Extensão Oceanos, eixo da Sustentabilidade, ao longo de um ano. $72 \%$ das repostas evidenciaram a importância destas atividades na formação dos estudantes e mudanças na sociedade, no entanto, esforços ainda são necessários para uma efetivação da informação. Assim, sugere-se uma educação transformadora a partir da construção coletiva para os problemas socioambientais.

Palavras-chave: Pesquisa-Ensino-Extensão; Meio Ambiente; Educação; Pesquisa.

Abstract: This theoretical-analytical study proposes a reflection on how environmental awareness can be improved in schools through continuous extensionist practices. An objective questionnaire, Likert scale, was applied in six schools in Itajaí (SC, Brazil), with 62 students involved in the activities of the Extension Project Oceanos, Sustainability theme, over one year. $72 \%$ of the answers highlighted the importance of these activities in the formation of students and changes in society, however, efforts are still needed for information effectiveness. Thus, it is suggested a transforming education from collective construction to the socio-environmental problems.

Keywords: Research-Education-Extension; Environment; Education; Research.

\footnotetext{
${ }^{1}$ Universidade do Vale do Itajaí - Instituto Federal de Educação, Ciência e Tecnologia do Paraná. E-mail: ana.bonassina@ifpr.edu.br, Link para o Lattes: http://lattes.cnpq.br/7708343878134526

2 Universidade do Vale do Itajaí. E-mail: kuroshima@univali.br.

Link para o Lattes: http://lattes.cnpq.br/8537824513641643
} 


\section{Introdução}

Atualmente, o conhecimento sobre sustentabilidade e responsabilidade social é bastante difundido nas mídias e nos espaços coletivos, no entanto, é comum ouvir as pessoas responsabilizarem os outros em relação aos problemas sociais e ambientais existentes, realçando em seus discursos a tácita ausência e a isenção do "eu". Costa e Schwanke (2011) afirmam que "é evidente a responsabilidade das entidades públicas e privadas para a diminuição dos impactos ambientais", e acrescentam que a "ação individual é extremamente importante e contribui para a formação de uma rede social onde é realizada a efetiva luta por melhores condições ambientais" (COSTA; SCHWANKE, 2011).

Para tratar dessa temática, este artigo discorre sobre a forma como a extensão universitária, no eixo da educação ambiental, pode contribuir para que os seres humanos vivam com maior qualidade de vida e de forma mais sustentável. Esse estudo se classifica como teórico e analítico, pois a partir da revisão de literatura, elaborou-se e aplicou-se um questionário aos professores, pedagogos ou diretores para se entender o problema de pesquisa aqui elencado: como a extensão universitária no domínio da educação ambiental tem sido colocada em prática. A metodologia desse estudo se encontra amparada nos estudos de Thiollent et al. (2003), Thiollent (2002) e Santos (2007).

Antes de se pensar na configuração da educação ambiental, é fundamental que se entenda como a metodologia da extensão universitária deve ser construída para que se chegue a bons resultados. A sociedade vive um novo período histórico e, dessa forma, conta com mudanças previsíveis e imprevisíveis ao mesmo tempo. E as universidades, a partir da extensão universitária, devem estar atentas a essas mudanças para que as demandas sociais, que, muitas vezes, aparecem na forma de vulnerabilidades, sejam sancionadas a fim de que se viva com mais qualidade. A extensão é fundamental para esse novo contexto, porque a universidade, a partir das suas três dimensões (ensino, pesquisa e extensão), pode contribuir, a partir de ações e projetos diversos, para que essas mudanças sejam passíveis de transformações sociais.

Para Thiollent (2002), materializada na forma de pesquisa, a produção do conhecimento é um processo que responde às mais diversas vulnerabilidades (ou demandas) sociais. Assim sendo, sempre realiza-se na interação entre diferentes agentes, especialistas, laboratórios, academias, firmas, estados, etc. Sabe-se, também, que a depender da área de atuação (que o autor denomina de ciências duras, ciências sociais e humanas, ciências fundamentais ou ciências aplicadas), bem como dos interesses, os mecanismos, ferramentas, objetivos e afins para a construção do conhecimento variam em termos de poder, recursos e compromissos (THIOLLENT, 2002; THIOLLENT et al., 2003; GADOTTI, 2017). Entendemos aqui que a extensão também é uma construção, ou melhor, uma reconstrução do conhecimento, 
resultado da troca de experiências que possibilitam cada ação de extensão, um aprendizado mútuo entre 0 conhecimento comunitário e 0 acadêmico (SANTOS, 2007).

Em detrimento disso, envolve uma série de agentes para pensar em determinada vulnerabilidade social; aqui será delimitada a de caráter ambiental com base na definição de como seria o resultado de processos sociais e mudanças ambientais (ESTEVES et al., 2017), a partir do conceito de vulnerabilidade como condição inerente ao ser humano, naturalmente necessitado de ajuda, referindo-se ao estado de ser/estar em perigo ou exposto a potenciais danos em razão de uma fragilidade atrelada à existência individual, rodeada de contradições (CARMO; GUIZARDI, 2018). Assim, é preciso considerar além dos universitários, os atores e públicos com culturas, interesses e níveis de educação diferenciados para que a extensão seja mais eficiente (THIOLLENT, 2002; THIOLLENT et al., 2003; GADOTTI, 2017). Dessa forma, a prática da pesquisa extensionista não pode se limitar apenas ao universo dos pesquisadores e responsáveis pelo projeto, ou seja, as avaliações devem abranger uma variedade de públicos externos. Assim, é fundamental que seja estabelecida uma parceria, com a participação da comunidade, para que se possa identificar problemas (vulnerabilidades) bem como para informar, capacitar e propor soluções aqui, nesse estudo, em relação à educação ambiental.

Segundo Thiollent (2002), ao se enfatizar a construção social, a metodologia pode abranger tanto a pesquisa quanto a extensão, ou seja, tanto o momento de produção como a sua difusão do conhecimento na sociedade. Isso ocorre em qualquer área do conhecimento, entretanto, é bastante recorrente na área das ciências humanas aplicadas (educação, gestão, comunicação, serviço social, desenvolvimento local, tecnologia apropriada etc). Com isso, percebe-se ser uma metodologia bastante pertinente em esferas nas quais o conhecimento pode ser, efetivamente, mobilizado e orientado para analisar problemas reais, bem como buscar soluções que sanem essas vulnerabilidades. Levam-se em consideração, na extensão, projetos que podem ser úteis para transformar a sociedade a curto ou médio prazo e a transformação do próprio sujeito da academia (SANTOS, 2007). A construção do conhecimento não só pode, mas deve se manifestar em cada tipo de atividade dos projetos extensionistas, através da pesquisa-ação, fortalecendo e evidenciando a indissociabilidade entre o ensino-pesquisa-extensão.

Pode se materializar nos diagnósticos e pesquisas efetuados em comunidades ou instituições; em ações formativas para membros dessas comunidades ou instituições; nas ações formativas para alunos, professores e técnico-administrativos da universidade ou, ainda, nas ações informativas ou mobilizadoras voltadas a públicos mais amplos. Para Thiollent (2002), isso implica na adesão de uma corrente mais participativa de construção do conhecimento. Parte-se do princípio de que a construção social do conhecimento pressupõe uma interação, assim como cooperação entre agentes distintos (THIOLLENT, 2002; THIOLLENT et al., 2003; GADOTTI, 
2017). É preciso, portanto, que a metodologia da pesquisa de extensão tenha ênfase participativa. Nesse caso, este trabalho se propõe a analisar, a partir de um questionário disposto em escala Likert, o que pensam esses agentes sobre a extensão na esfera da educação ambiental.

Essa participação, por sua vez, pode ser implícita e explícita ao mesmo tempo. Nesse sentido, como se parte de uma metodologia calcada no contexto social, a participação de diferentes atores se torna imprescindível. É comum que equipes de especialistas lidem, de forma participativa, com os stakeholders oriundos de programas sociais e planos de desenvolvimento rural, local ou sustentável, bem como com a educação e gestão voltadas para o meio ambiente. Assim sendo, a pesquisa-ação é recomendada para que, a partir de um espaço de interlocução, os atores implicados participem do processo de resolução dos problemas por meio da oferta de conhecimentos diferenciados, bem como de proposição de soluções de forma ativa. É comum, ainda, que, nesse espaço, os pesquisadores, extensionistas e consultores exerçam um papel articulador e facilitador para com os interessados.

Esse estudo justifica a sua relevância porque pretende atrelar as contribuições teóricas com as percepções de diferentes agentes frente às vulnerabilidades sociais na prática extensionista na esfera da educação ambiental, assim sendo, um capítulo teórico e outro analítico são fundamentais para que essa metodologia possa se manifestar. Ela pode tomar proporções positivas quando se enfatizam, ao mesmo tempo, as suas dimensões participativa, crítica e emancipatória. Soluções apenas podem ser construídas de forma coletiva e, é por isso, que a extensão é essencial nesse processo de busca pela extinção ou amenização de problemas reais da sociedade (THIOLLENT, 2002; THIOLLENT et al., 2003; GADOTTI, 2017). É por meio da consideração de vozes distintas, bem como a partir do acesso ao conhecimento teórico-metodológico, que se chegam a estratégias para tornar o mundo que habitamos mais sustentável.

\section{A importância da sustentabilidade nas práticas educativas}

Discussões frente às práticas sociais emergentes de um contexto marcado pela degradação permanente do meio ambiente e do seu ecossistema têm sido necessárias. Isso envolve a necessidade da articulação com a produção de sentidos sobre a educação ambiental (LOUREIRO, 2004a; JACOBI, 2004; TUMELERO; BAHIA, 2018). A extensão pode contribuir com essa articulação, pois a dimensão ambiental se configura como uma questão que envolve um conjunto de atores do universo educativo para potencializar o engajamento dos diversos sistemas do conhecimento, assim como a formação de profissionais e comunidade universitária interdisciplinar para que a sustentabilidade, a partir das atividades extensionistas, possa ser colocada em prática a fim de que os problemas ambientais sejam amenizados ou solucionados. É preciso, portanto, que se estabeleça uma perspectiva interdisciplinar que una o ensino, a pesquisa e a extensão para que a educação ambiental alcance bons resultados.

Revbea, São Paulo, v.16, № 1: 163-180, 2021. 
É indispensável que o processo de produção do conhecimento contemple as inter-relações do meio natural com o social (GOLÇALVES, 2019). Para isso, deve-se incluir a análise dos determinantes do processo; o papel dos diversos atores envolvidos, bem como as formas de organização da sociedade que potencializam o poder das ações interventivas para que se amenize um determinado problema social na esfera ambiental (TRISTÃO, 2013; LOUREIRO, 2004b; LEFF, 2009). Assim sendo, é preciso aderir a uma perspectiva que prioriza um novo perfil de desenvolvimento, ou seja, é fundamental seguir uma corrente que enfatiza a sustentabilidade socioambiental (LOUREIRO, 2004a; JACOBI, 2004). Esse desenvolvimento sustentável não faz referência, apenas, a problemas oriundos de adequações ecológicas de um processo social. Trata-se de uma estratégia ou modelo múltiplo para essa sociedade, que, por sua vez, precisa considerar uma viabilidade econômica ecológica.

Estudos apontam, ainda, que o enfoque do desenvolvimento sustentável se pauta na sua capacidade de ideia-força (LOUREIRO, 2004a) bem como nas suas repercussões intelectuais e no papel articulador de discursos e práticas múltiplas. Não segue fragmentos de uma matriz única que toma forma a partir de crises ambientais, econômicas e sociais. Para Loureiro (2004a), vive-se em um estado de emergência que se materializa em razão de uma crise no estilo de pensamento, dos imaginários sociais e do conhecimento que sustentam a modernidade. Essa crise se manifesta de forma ampla e abrangente nos espaços internos dos sujeitos; nas condutas sociais autodestrutivas; nos espaços externos; na degradação da natureza e na qualidade de vida das pessoas. É nesse contexto que a extensão deve agir. A partir de projetos inovadores e eficientes, deve-se caminhar para o incentivo à educação ambiental para que esses problemas possam ser combatidos antes que seja tarde.

É fundamental, portanto, que a educação se oriente, de forma decisiva, para que seja possível fazer com que essa geração, assim como as futuras, entendam a importância de se buscar a sustentabilidade e a preservação dos recursos naturais para que as próximas gerações tenham igual acesso. Práticas extensionistas dentro das escolas dos mais diversos níveis são importantes para que essa conscientização seja efetiva (LOUREIRO, 2004a; JACOBI, 2004; TRISTÃO, 2013; LOUREIRO, 2004b; LEFF, 2009). Os sujeitos não devem, apenas, aceitar a incerteza em relação ao futuro, devem ser capazes de pensar de forma mais ampla e crítica, e, assim, estarem mais abertos frente às indeterminações, mudanças, diversidades e possibilidades de construir e reconstruir o conhecimento sobre o mundo que os cerca. Trata-se de um processo contínuo de novas leituras e interpretações que configuram novas possibilidades de ações transformadoras, possíveis apenas por meio da educação.

Deve-se, então, refletir sobre os desafios para que se estabeleçam novas formas de pensar e agir frente às questões de caráter ambiental (TRISTÃO, 2013; LOUREIRO, 2004b; LEFF, 2009). É impossível resolver os 
crescentes e complexos problemas ambientais, assim como reverter as suas causas, sem que se recaia em uma mudança radical nos sistemas de conhecimento, nos valores, ideias e crenças e nos comportamentos gerados pela dinâmica da racionalidade em voga que é fundamentada a partir de diretrizes econômicas quando se pensa em desenvolvimento (LEFF, 2009). Nesse contexto, refletir sobre a complexidade ambiental faz com que seja possível compreender como diferentes atores sociais se mobilizam ao se apropriarem da natureza. É possível pensar, também, em um processo educativo articulado e comprometido com a sustentabilidade a ser garantida por meio da participação coletiva, uma das diretrizes que norteiam a extensão universitária.

Para tanto, deve-se priorizar a interdisciplinaridade entre diferentes áreas do saber (LOUREIRO, 2004a; JACOBI, 2004; TRISTÃO, 2013; LOUREIRO, 2004b; LEFF, 2009; GOLÇALVES, 2019). É necessário que se questionem valores e premissas que norteiam as práticas sociais atuais, ou seja, isso implica em uma mudança na forma de pensar e agir frente ao mundo. A extensão universitária pode fazer com que seja possível transformar o conhecimento e as práticas educativas que não priorizam ou pouco falam sobre a importância do desenvolvimento sustentável. Assim sendo, exige-se que haja uma inter-relação entre saberes e práticas coletivas que criam identidades e valores em comum, bem como ações solidárias em relação à natureza (LOUREIRO, 2004a). O diálogo entre esses saberes diversos é essencial, afinal, com os problemas ambientais se tornando, a cada dia, mais abrangentes, crescem os riscos socioambientais que causam danos severos à humanidade. Desvelada essa realidade, pode-se pensar que a ação do ensino, da pesquisa e da extensão é uma das estratégias possíveis para a mitigação dos problemas socioambientais.

Deve-se iniciar, para isso, segundo Loureiro (2004a), uma mudança na escala de análise dos problemas ambientais e, assim, compreender que estes problemas ambientais, cada vez mais frequentes e imprevisíveis, sejam assimilados como parte da realidade global. Torna-se fundamental, então, que seja construído e fortalecido um ideário frente à importância da sustentabilidade ambiental que apenas pode ser conseguido por meio da educação transformadora, que pode ser potencializada via pesquisa e extensão. Uma estratégia eficiente é o aumento do poder de iniciativas que privilegiam o acesso à informação e à transparência para a administração dos problemas ambientais e urbanos.

Diante do exposto torna-se evidente a utilização de estratégias que busquem amenizar as vulnerabilidades da sociedade contemporânea. A Extensão Universitária, com foco na sustentabilidade ambiental, pode estimular o avanço do conhecimento sustentável nos diferentes espaços. Esse estudo, embasado na metodologia de avaliação de Pocho (2011), pode atuar como uma ferramenta avaliativa para propor novos olhares sobre os problemas pontuais de um projeto, cabendo a cada instituição, mediante a apresentação 
dos dados, estabelecer estratégias próprias para deixar a sua marca no processo de desenvolvimento sustentável no país.

\section{Metodologia - Percepções de professores e gestores das escolas de ensino médio sobre a educação ambiental}

Este artigo tem por base as informações coletadas no Projeto Oceanos, projeto de extensão universitária que objetiva popularizar os conhecimentos de oceanografia e sustentabilidade à comunidade litorânea, e tem como escopo, conscientizar estudantes a preservar os ambientes marinhos por meio do conhecimento.

O Projeto Oceanos está ativo há 12 anos e trabalhou durante o ano de 2018 com 206 jovens filiados ao Instituto Crescer (IC). Os participantes da pesquisa são estudantes da educação básica e se encontram em situação de vulnerabilidade social. Esses estudantes frequentaram o IC por um ano, com o intuito de preparar-se para o primeiro emprego, logo, quatro vezes por semana, no contraturno escolar, dentro dos espaços da Universidade do Vale do Itajaí, participaram de aulas de Comunicação Oral e Escrita, Ética/Cidadania/Relações Interpessoais, Matemática, Mundo do trabalho e Sustentabilidade.

O projeto Oceanos se insere, no IC, na área de ação "sustentabilidade" e foi planejado com 64 encontros distribuídos entre os meses de maio e dezembro de 2018. Para as atividades, os estudantes do IC foram subdivididos em 8 turmas de aproximadamente 25 alunos que participaram mensalmente das atividades promovidas pelos professores, pesquisadores e estagiáriosbolsistas do Projeto Oceanos. Assim, os encontros, com duração de quatro horas cada, foram organizados de forma que cada estudante do IC participasse das atividades do projeto uma vez ao mês. Considerando que havia oito turmas de estudantes, cada atividade mensal era repetida oito vezes. Os temas abordados objetivaram suscitar o interesse dos estudantes pelas causas ecológicas e problemas socioambientais.

Para compreender como agentes diversos vinculados à educação têm se posicionado frente à extensão universitária na área da educação ambiental, e especialmente a este Projeto Oceanos, aplicou-se um questionário com 27 perguntas aos professores e gestores das escolas de origem de cada estudante. As escolhidas foram aquelas que continham o maior número de estudantes participantes do Projeto Oceanos.

O referido instrumento baseia-se nos estudos de Pocho (2011), que tratam sobre a elaboração de um sistema de medição de avaliação de programas sociais no âmbito das políticas públicas.

Para esse trabalho, as questões foram dispostas em uma tabela de escala likert que compreendeu a atribuição de conceitos de nível de concordância de 1 a 5, sendo: 1 (muito baixo), 2 (baixo), 3 (neutro), 4 (alto) e 5 (muito alto). O conteúdo das questões objetivou entender de que modo as 
atividades de extensão universitária sobre a temática sustentabilidade impactaram os estudantes envolvidos em suas escolas de ensino formal, ou seja, como estes estudantes levaram a informação para suas escolas e de que forma impactaram outros estudantes e professores (sujeitos que não estavam envolvidos no projeto).

As escolas em que se aplicou o instrumento são estaduais e municipais, abrigam estudantes de 14 a 18 anos e localizam-se no município de Itajaí (SC), tendo sido selecionadas por terem o maior número de estudantes associados ao Instituto Crescer, frequentadores do eixo sustentabilidade, ao qual é organizado pelo Projeto Oceanos. As escolas foram visitadas no mês de outubro de 2018 por uma doutoranda vinculada ao projeto e uma assistente social vinculada ao Instituto Crescer, as quais, em reunião previamente agendada, apresentaram 0 trabalho realizado e convidaram os sujeitos (professores/diretores/pedagogos) para participarem da pesquisa. Das 18 escolas estaduais do município, 12 foram visitadas para este trabalho por possuírem mais de 2 estudantes matriculados em seus estabelecimentos e, concomitantemente, participar do projeto de extensão Oceanos.

\section{Resultados e discussões}

Em outubro de 2018 foram visitadas 12 escolas estaduais do município de Itajaí, selecionadas por possuírem maior número de alunos associados ao projeto Oceanos, variando de 2 a 22 estudantes por escola, contemplando um total de 115 estudantes. Tais escolas, representadas por diretores e/ou pedagogos, concederam, antecipadamente, um horário para a conversa com a pesquisadora e assistente social e, no ato da visita, receberam o Termo de Consentimento Livre e Esclarecido (TCLE) devidamente aprovado pelo comitê de ética da universidade (CEP № 3.534.576). Entre diretores e/ou pedagogos das 12 escolas abordadas, 4 instituições não retornaram o questionário e 2 responderam de forma insatisfatória, logo, serão apresentados os resultados das respostas de 6 representantes das escolas (professores, diretores ou pedagogos), que representam um total de 62 alunos participantes do Projeto Oceanos. Como o questionário era longo e necessitava de um momento de reflexão, as respostas foram retornadas por e-mail, após um período, deixando os diretores, pedagogos e professores que participaram desta pesquisa bem à vontade para responderem e questionar os demais colaboradores, caso necessário, ou mesmo retornar mensagens para maiores esclarecimentos. As perguntas do instrumento foram aglutinadas por indicadores, de acordo com os direcionamentos do trabalho de Pocho (2011), e na sequência, reunidas em 3 grupos para a discussão deste artigo. A divisão encontra-se na tabela a seguir. 
Tabela 1: Relação das 27 perguntas aplicadas nesta pesquisa, categorizadas em 3 Grupos e 11 Indicadores.

\begin{tabular}{|c|c|c|}
\hline Grupos & Indicador & Perguntas \\
\hline \multirow{5}{*}{ 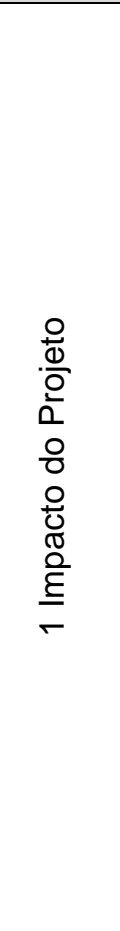 } & $\begin{array}{l}1- \\
\text { Aprendizagem } \\
\text { dos } \\
\text { participantes }\end{array}$ & $\begin{array}{l}\text { O Programa promove a construção das competências necessárias à } \\
\text { preparação dos sujeitos para atuarem na gestão ambiental, conforme } \\
\text { as competências de referência listadas abaixo e as demais } \\
\text { competências indicadas no planejamento do Programa? }\end{array}$ \\
\hline & $\begin{array}{l}2 \text { - Impacto das } \\
\text { ações }\end{array}$ & $\begin{array}{l}\text { O percentual de Beneficiários impactados pelas ações de melhoria } \\
\text { socioambiental, fruto da participação comunitária em relação aos } \\
\text { beneficiários do projeto coletivo no âmbito do Programa de Educação } \\
\text { Ambiental, evidencia que o maior número de sujeitos impactados pelos } \\
\text { projetos, desdobramentos do Programa de Educação ambiental, o } \\
\text { foram por meio de medidas de melhoria socioambiental } \\
\text { implementadas? Este percentual indica o maior foco dos projetos em } \\
\text { ações concretas para a mudança na realidade? }\end{array}$ \\
\hline & \multirow{2}{*}{$\begin{array}{l}3 \text {-Resolução de } \\
\text { conflitos }\end{array}$} & $\begin{array}{l}\text { O Programa propiciou a leitura crítica e compreensão da dinâmica } \\
\text { sociopolítica dos conflitos, problemas e/ou riscos socioambientais } \\
\text { identificados? }\end{array}$ \\
\hline & & $\begin{array}{l}\text { O Programa propiciou a elevação da capacidade de resolver } \\
\text { problemas materiais na região, por exemplo, nutrição, renda, trabalho, } \\
\text { habitação, de modo a contribuir para a resolução de conflitos, } \\
\text { problemas e/ou riscos socioambientais? }\end{array}$ \\
\hline & $\begin{array}{l}4 \text {-Melhoria da } \\
\text { comunidade } \\
\text { envolvida }\end{array}$ & O Programa propiciou melhoria do aluno em seu sentido global? \\
\hline \multirow{5}{*}{ 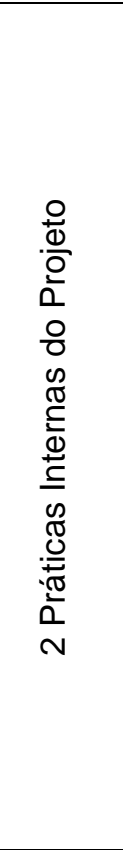 } & \multirow{3}{*}{$\begin{array}{l}5 \text { - } \\
\text { Disseminação } \\
\text { da Informação }\end{array}$} & $\begin{array}{l}\text { Há registros sobre eventos/cursos de disseminação das informações } \\
\text { sobre as questões socioambientais no âmbito dos Projetos coletivos } \\
\text { de Educação Ambiental? }\end{array}$ \\
\hline & & $\begin{array}{l}\text { Foram realizados eventos/cursos no âmbito dos Projetos coletivos de } \\
\text { Educação Ambiental para disseminar as informações sobre as } \\
\text { questões socioambientais para as comunidades, considerando os } \\
\text { problemas, riscos e conflitos socioambientais da região? }\end{array}$ \\
\hline & & $\begin{array}{l}\text { Considerando os objetivos dos Projetos, os eventos/cursos realizados } \\
\text { foram relevantes para disseminar as informações sobre as questões } \\
\text { socioambientais para as comunidades, tendo em vista a busca e } \\
\text { implementação de soluções para os problemas, riscos e conflitos } \\
\text { socioambientais da região? }\end{array}$ \\
\hline & \multirow[t]{2}{*}{$\begin{array}{l}6 \text { - Efetivação da } \\
\text { Informação }\end{array}$} & $\begin{array}{l}\text { O Programa trabalhou adequadamente a perspectiva da gestão } \\
\text { ambiental no âmbito de políticas públicas, de modo que os projetos } \\
\text { coletivos de Educação Ambiental consideraram, em seu planejamento } \\
\text { e execução, a inserção da temática ambiental em outros programas e } \\
\text { projetos existentes, de modo a ampliar os resultados esperados? }\end{array}$ \\
\hline & & $\begin{array}{l}\text { A inserção da temática ambiental nos programas e projetos } \\
\text { possibilitou a ampliação do acesso às informações sobre meio } \\
\text { ambiente para beneficiários diretos, indiretos e comunidades em } \\
\text { geral? }\end{array}$ \\
\hline
\end{tabular}

Continua... 
...continuação.

\begin{tabular}{|c|c|c|}
\hline Grupos & Indicador & Perguntas \\
\hline 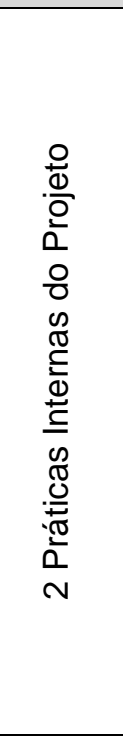 & $\begin{array}{l}7 \text { - Abrangência } \\
\text { esperada }\end{array}$ & 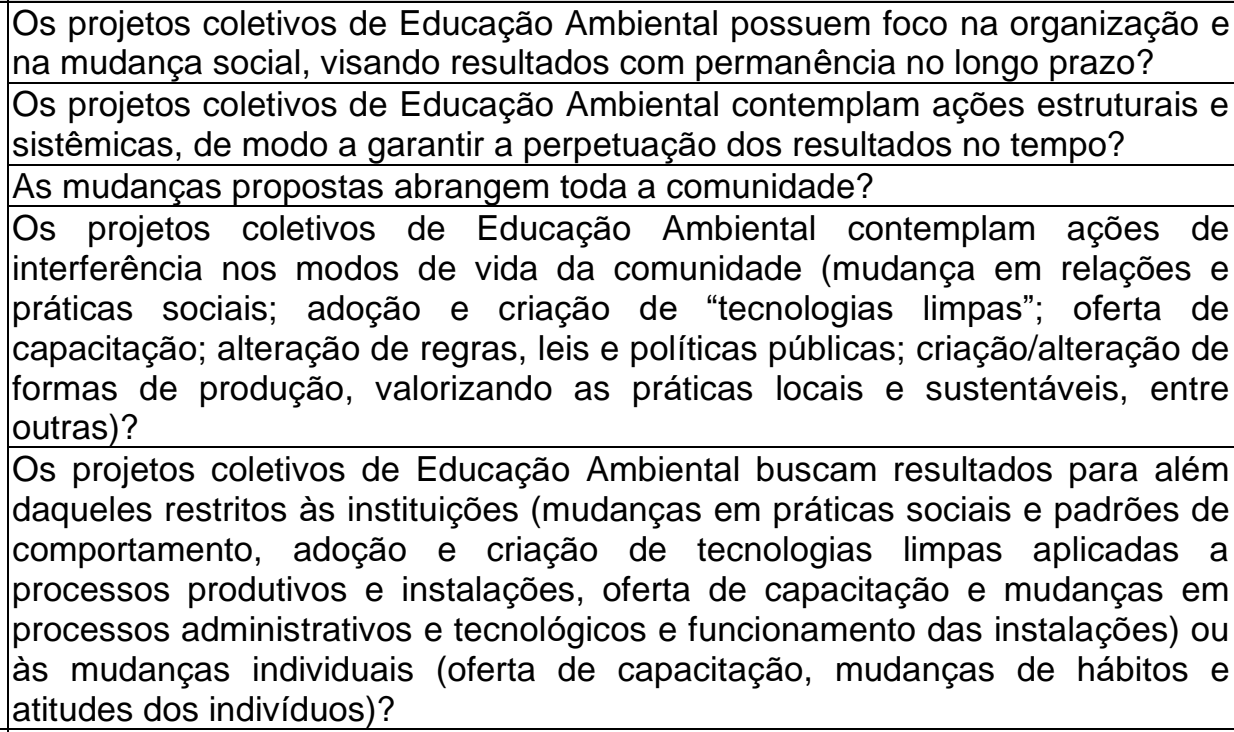 \\
\hline \multirow{4}{*}{ 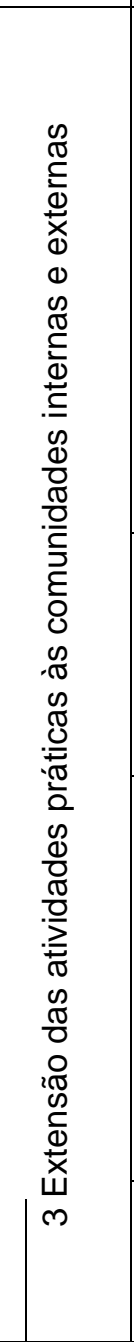 } & $\begin{array}{l}8 \text { - Legado } \\
\text { Cultural }\end{array}$ & $\begin{array}{l}\text { O Programa de Educação Ambiental promove um diálogo entre as práticas } \\
\text { sociais afetas à cultura local com suas tradições e costumes, e sua relação } \\
\text { com a sustentabilidade socioambiental da região? } \\
\text { A condução do Programa de Educação Ambiental contempla o respeito ao } \\
\text { contexto cultural dos participantes, suas vivências, necessidades e } \\
\text { motivações, dando voz e autoria para estes ao longo da estruturação e } \\
\text { execução do Programa? } \\
\text { O Programa de Educação Ambiental promove a construção do conhecimento } \\
\text { a partir dos diversos saberes produzidos pelos sujeitos do Programa? } \\
\text { O Programa leva o participante a pensar e a questionar a situação atual de } \\
\text { seu grupo social através da reflexão sobre seu passado, pois o legado cultural } \\
\text { constitui-se em um meio para se construir a relação entre identidade e } \\
\text { comunidade local? }\end{array}$ \\
\hline & $\begin{array}{l}9 \text { - Construção } \\
\text { de uma } \\
\text { sociedade } \\
\text { equilibrada }\end{array}$ & $\begin{array}{l}\text { Tendo em vista os objetivos e ações do Programa, os dados apresentados } \\
\text { são relevantes para a medição dos resultados esperados? } \\
\text { Há registros sobre índices de Redução dos problemas ambientais, como por } \\
\text { exemplo, aqueles referentes à poluição, lixo, escassez de água, efeito estufa, } \\
\text { chuva ácida, perda da biodiversidade, desmatamento, considerando os } \\
\text { objetivos e ações do Programa? }\end{array}$ \\
\hline & $\begin{array}{l}\text { 10-Atendimento } \\
\text { aos beneficiários }\end{array}$ & $\begin{array}{l}\text { A quantidade de beneficiários atendidos pelos projetos coletivos de Educação } \\
\text { Ambiental é compatível com a necessidade de busca de alternativas para a } \\
\text { resolução dos riscos, problemas e/ou conflitos tratados pelo Programa? } \\
\text { Os projetos coletivos de Educação Ambiental elaborados propiciam um } \\
\text { impacto significativo em termos de atendimento aos beneficiários indiretos do } \\
\text { Programa de Educação Ambiental? } \\
\text { Os tipos de beneficiários atendidos são aqueles sujeitos que necessitam de } \\
\text { participar das iniciativas de busca de alternativas para a resolução dos } \\
\text { problemas, riscos e/ou conflitos socioambientais identificados e a melhoria da } \\
\text { qualidade de vida de todos? }\end{array}$ \\
\hline & $\begin{array}{l}\text { 11-Abrangência } \\
\text { obtida }\end{array}$ & $\begin{array}{l}\text { Os projetos coletivos de Educação Ambiental que visam a intervenção na } \\
\text { realidade tiveram foco na melhoria das condições de vida das } \\
\text { comunidades/beneficiários do Programa, incluindo ações de melhoria nos } \\
\text { diversos espaços sociais existentes? }\end{array}$ \\
\hline
\end{tabular}

Revbea, São Paulo, v.16, № 1: 163-180, 2021. 
Os resultados foram analisados por Grupos de Categorização dos indicadores, sendo: 1 - Impactos do Projeto, abrangendo 5 perguntas, organizadas pelos 4 indicadores, 2 - Práticas Internas do Projeto, abrangendo 10 perguntas e três indicadores e 3 - Extensão das atividades práticas às comunidades internas e externas, englobando 10 perguntas e 4 indicadores (Tabela 1). Os resultados obtidos revelam o impacto que o Projeto Oceanos provocou sobre os estudantes e de que forma isso reverberou na escola onde estudam, segundo as percepções dos entrevistados (Figura 1).

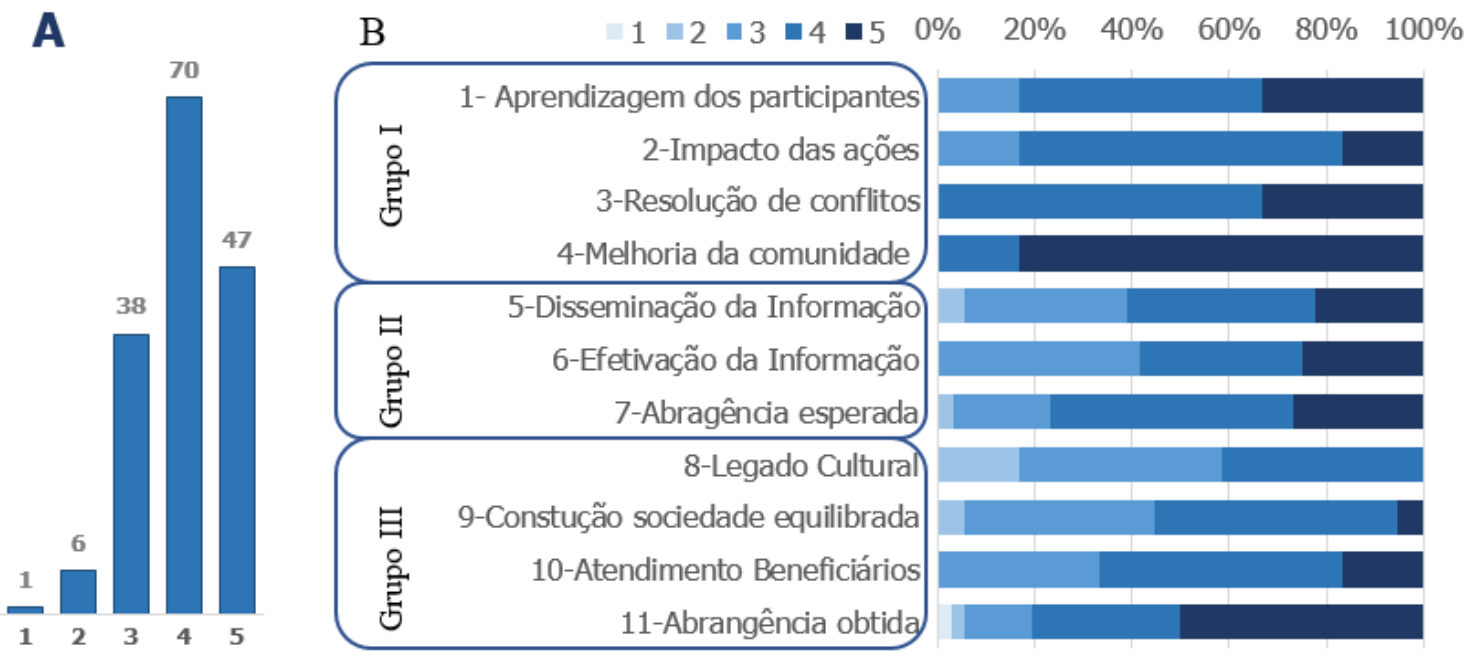

Figura 1: Distribuição das repostas dos participantes da pesquisa. A - Distribuição de todas as respostas por conceito de concordância e B - Distribuição percentual das respostas ao longo dos 11 Indicadores, categorizadas nos três Grupos de Categoria. Conceito de Concordância: 1 - muito baixo; 2 - baixo; 3 - neutro; 4 - alto e 5 - muito alto.

Fonte: autoria própria.

Para esta análise, consideraram-se as respostas das seis escolas, que responderam as 27 perguntas, totalizando 162 respostas, distribuídas ao longo das cinco categorias de concordância (escala de 1 a 5) (Figura 1A). De maneira geral, os representantes das escolas percebem a importância da participação dos seus alunos em atividades extraclasse e seu impacto sobre a sustentabilidade. Observou-se que, $72 \%$ de todas as respostas foram categorizadas nos dois conceitos que melhor representam esta concordância, sendo, 70 respostas para o conceito " 4 " $(43 \%)$ e 47 respostas para o conceito máximo (29\%) (Figura 1A), evidenciando assim, a percepção dos professores da importância destas atividades de sustentabilidade na formação dos seus alunos e suas mudanças na sociedade. Estas respostas distribuídas ao longo dos indicadores mostraram que os mais bem avaliados foram os indicadores " 4 - Melhorias da comunidade" e "11 - Abrangência obtida", respectivamente com $83 \%(\mathrm{~N}=5)$ e $50 \%(\mathrm{~N}=18)$ das respostas no conceito máximo (Figura 1B). E o conceito 4, o mais avaliado pelos participantes, foi distribuído ao longo de todos os indicadores, com um percentual médio de $45 \%$. O Conceito 1 - muito baixa concordância - apareceu em apenas uma única resposta, no indicador 11. 
O primeiro Grupo de Indicadores, denominado de "Impactos do Projeto", formado pelos quatro primeiros indicadores (Tabela 1 e Figura 2) revela 0 impacto provocado nos estudantes pelo projeto e a forma como reverberou na escola onde estudam. Segundo a análise dos professores/diretores e pedagogos, o projeto provocou "alto impacto" (conceito 4) e "muito alto" (conceito 5) em todos os indicadores (Figura 2). O indicador mais bem avaliado, conceito máximo (Figura 2D), foi "Melhoria da Comunidade envolvida", com $83 \%$ das respostas, evidenciando que o projeto propiciou melhoria do estudante em seu sentido global. Logo, o projeto promoveu, por meio da mobilização, organização e participação social, competências aos estudantes em provocar mudanças sociais no que diz respeito à melhoria da qualidade de vida. $\mathrm{O}$ que leva a perceber que os esforços realizados para a inclusão da temática ambiental foram notados, não só no conhecimento, mas também na postura, na atuação social ativa e na consciência ambiental e cidadã.

A

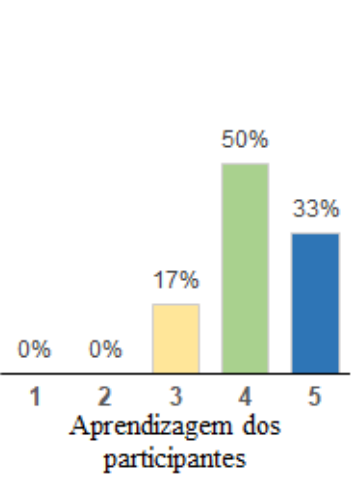

B

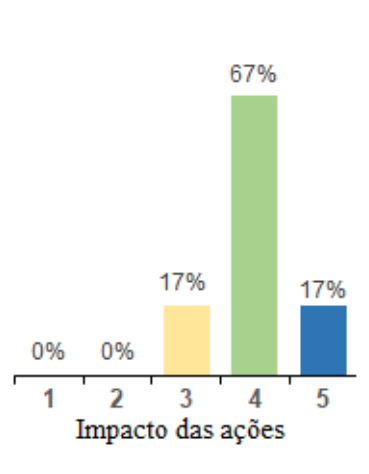

C

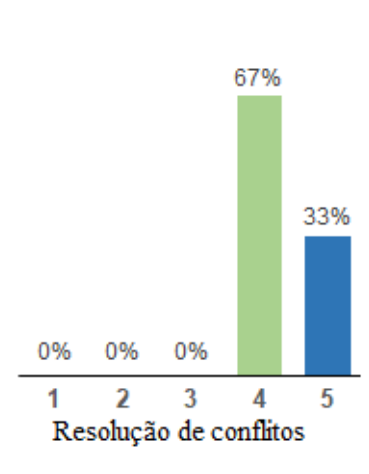

D

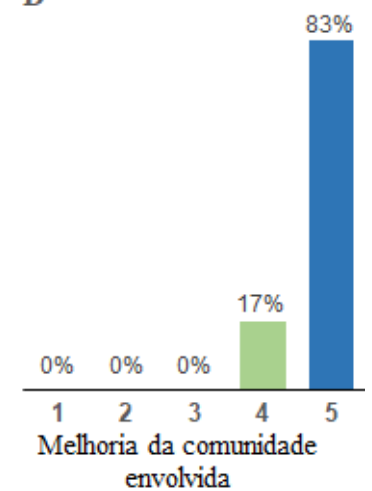

Figura 2: Distribuição do percentual das respostas dos participantes em relação aos quatro indicadores do Agrupamento 1 - Impactos do projeto, em cada conceito de concordância. Os conceitos de concordância foram classificados de 1 a 5, sendo: 1- muito baixo; 2 - baixo; 3 - neutro; 4 - alto e 5 - muito alto.

Fonte: autoria própria.

Dois indicadores deste grupo apresentaram o conceito neutro (conceito 3), o mais baixo dentre os apresentados, indicando necessidades de melhorias, sendo a "Aprendizagem dos participantes" e "Impacto às ações", com $17 \%$ das respostas neste conceito (Figura $2 \mathrm{~A}$ e 2B). Assim, há a necessidade de avaliar se o projeto possibilitou aos estudantes formas de multiplicar o conhecimento por meio de ações de melhoria socioambiental.

Os entrevistados perceberam que as medidas adotadas para melhorar as questões socioambientais dos beneficiários impactados foram concretizadas por meio de ações que resultaram na mudança na realidade local. No entanto, como visto na Figura $2 \mathrm{~B}$, é possível ampliar as ações para que mais pessoas se tornem conscientes, afinal, "educandos de hoje, são, e serão os consumidores de amanhã" (TUMELERO, BAHIA, 2018, p. 125). Atividades extensionistas podem acelerar esse processo. Santos, Maccari e Seixas (2016, 
$\mathrm{s} / \mathrm{p}$ ) constatam em sua pesquisa que "o trabalho de extensão está colaborando no processo de intervenção e consequentemente na transformação do públicoalvo, tornando pessoas mais críticas, capazes de refletirem sobre as realidades e sobre os fatos para melhorar a qualidade de vida, pessoal e da comunidade."

O próximo Grupo de categorização, denominado "Práticas internas do projeto" (Figura 3), pretendeu entender como se deu a realização dos eventos, e qual foi a efetividade dessa disseminação de informações no projeto, desvelando, desta forma sua abrangência e efetividade.

A

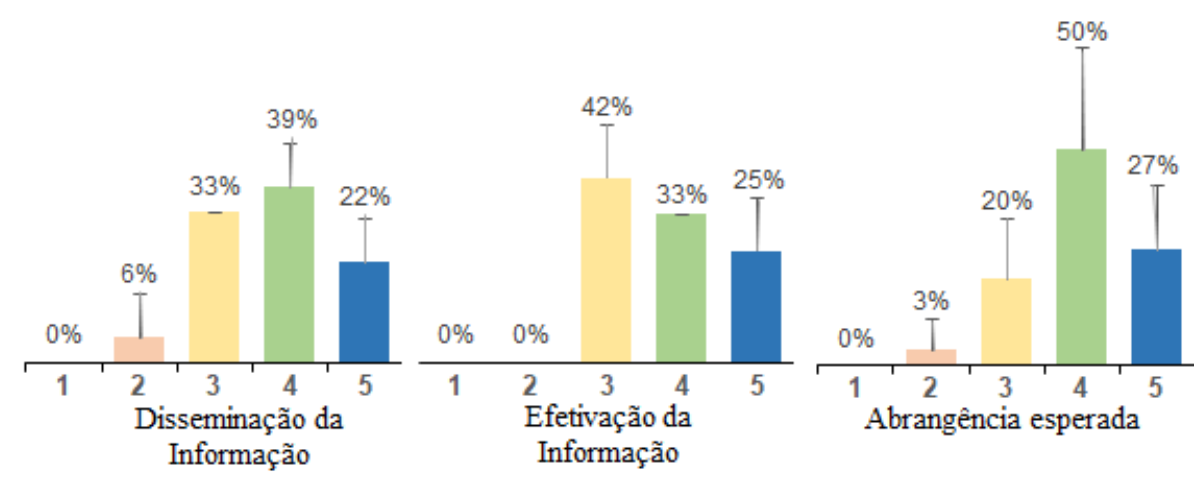

Figura 3: Distribuição do percentual das respostas dos participantes em relação aos três indicadores do Agrupamento 2 -Práticas Internas, em cada conceito de concordância. Os conceitos de concordância foram classificados de 1 a 5 , sendo: 1 - muito baixo; 2 - baixo; 3neutro; 4 - alto e 5 - muito alto.

Fonte: autoria própria.

Neste grupo as repostas já foram bem menos avaliadas em relação ao Grupo 1. Os conceitos 3, 4 e 5 foram distribuídos ao longo dos três indicadores, com uma representatividade que variou entre $20 \%$ e $50 \%$ (Figura 3 ). O indicador "Disseminação da Informação" (Figura 3A), aponta um bom nível de concordância, no entanto, ainda pode ser melhorado, visto que há sinalizações no conceito 2 (baixa concordância) e 3 (neutro) que totalizaram 39\%. Diante disso, podemos indicar que novas estratégias para a detecção de problemas, riscos e conflitos socioambientais da região sejam mais bem explorados para que soluções mais efetivas sejam colocadas em prática. Lorenzetti (2008) afirma que, muitas vezes, a disseminação do conhecimento ecológico fica restrita apenas à teoria, necessitando de ações efetivas com vistas a estimular a participação ativa do estudante, provavelmente, a continuidade destas atividades, com inserção da aplicação dos conceitos teóricos na comunidade local, pode ser uma sugestão para melhoria destes conceitos.

Já no indicador "Efetivação da Informação" (Figura 3B) foram propostas duas perguntas referentes à inserção de informações sobre meio ambiente em projetos no âmbito de políticas públicas existentes, obtendo como resultado a maior média registrada de 3 pontos (neutra), o que demonstra a importância 
das instituições trabalharem de forma mais eficiente e urgente a temática ambiental em suas políticas públicas.

Percebe-se que, mesmo de forma tímida, as instituições possibilitaram a ampliação do acesso à informação e buscaram incluir a temática ambiental nos seus projetos. Isso pode ser constatado quando os sujeitos apontam para o grau 4 (alto) da tabela likert. As ações extensionistas podem ser poderosas aliadas para a melhora deste índice nesse processo. Incrocci e Andrade (2018) esclarecem que, o fortalecimento da extensão perpassa pelos mecanismos e ações que qualificam o processo para a melhoria social, logo é preciso que as escolas, por meio da extensão universitária, por exemplo, incorporem, em suas políticas, projetos eficientes para o combate à desinformação ambiental.

O indicador "Abrangência Esperada dos impactos" (Figura $3 \mathrm{C}$ ) se propôs a entender como os projetos inferiram na comunidade de forma a provocar mudanças positivas e duradouras, assim sendo, foram realizadas 5 perguntas para dimensionar este indicador. Observou-se que $77 \%$ das respostas apontaram para os conceitos 4 (alta) e 5 (muito alta), logo, os entrevistados concordam que os projetos impactaram positivamente os estudantes, abrangendo, desta forma, toda a comunidade, com foco na mudança social alicerçados nas ações estruturais, sistêmicas, positivas e duradouras (POCHO, 2011).

O último agrupamento (Figura 4) destinou-se a entender, de forma geral, em que medida o projeto se disseminou dentro do contexto ao qual o estudante está inserido, por isso, denominado de "Extensão das atividades práticas às comunidades internas e externas". Agrupou 4 indicadores, representados por 12 perguntas.

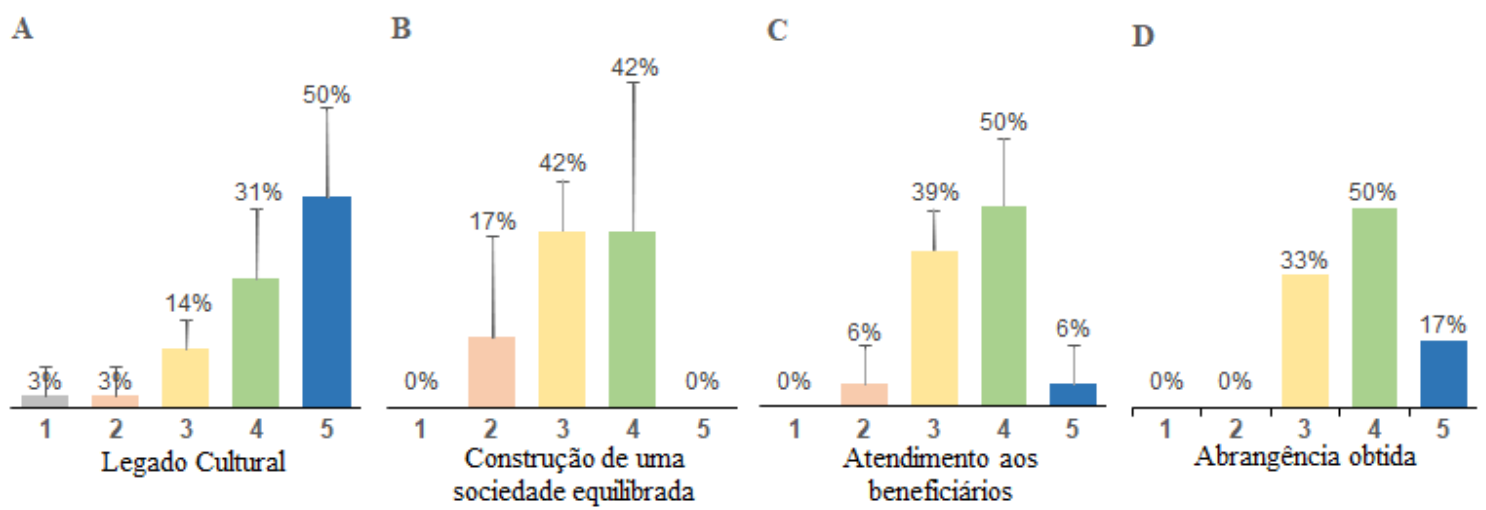

Figura 4: Distribuição do percentual das respostas dos participantes em relação aos quatro indicadores do Agrupamento 3 - Extensão Comunitária, em cada conceito de concordância. Os conceitos de concordância foram classificados de 1 a 5, sendo: 1 - muito baixo; 2 - baixo; 3 - neutro; 4 - alto e 5 - muito alto.

Fonte: autoria própria.

O indicador "Legado Cultural" (Figura 4A) -, com seis questões, remete ao atendimento às necessidades de preservação do legado cultural e fortalecimento da identidade cultural local dos grupos sociais. Constatou-se que Revbea, São Paulo, v.16, № 1: 163-180, 2021. 
$50 \%$ dos participantes entendem que as atividades auxiliaram no atendimento das necessidades do legado cultural e fortalecimento da identidade local, somados aos $31 \%$ com um nível de concordância alto (conceito 4), estes resultados fortalecem esta evidência. Pocho (2011, p. 265) contribui afirmando que as ações nos processos educativos devem contemplar uma "visão da história dos diversos grupos sociais, visando favorecer o reconhecimento e o respeito à pluralidade". Diante do resultado, é possível alegar que o projeto respeitou a visão da história dos estudantes e favoreceu o reconhecimento e o respeito dos diversos grupos presentes.

O indicador "Construção de uma sociedade equilibrada" (Figura 4B), exibe preferência aos conceitos 3 e 4, mostrando ser preciso ampliar o trabalho no que se refere aos índices de Redução dos problemas ambientais e medição dos resultados esperados com vistas a promover aos sujeitos um olhar mais voltado ao "eco-consumo" (TUMELERO, BAHIA, 2018, p.138).

Os dois outros indicadores (Figuras 4C e 4D) deste grupo apresentaram comportamentos similares com predominância do conceito 4 (alta concordância), representando em torno de $50 \%$ das respostas. Estes resultados revelam forte atuação extensionista ou outras ações, com vistas, por exemplo, a combater o desperdício e o consumismo e otimizar os recursos naturais existentes, temas trabalhados ao longo das atividades. Estes indicadores possibilitam o entendimento relacionado à busca por alternativas voltadas à resolução de problemas e/ou conflitos ambientais e o atendimento aos beneficiários indiretos, revelando-se muito bom, no entanto, com possibilidades de aperfeiçoamento, com vistas a ampliar a conscientização das pessoas. Matos e Dantas (2018, p. 182) alertam ser preciso "uma valorização de políticas voltadas para o esclarecimento quanto ao consumo descontrolado, incitando aos indivíduos para uma decisão mais consciente." Entretanto, é vital mencionar que as questões ambientais são desafios já conhecidos e de difícil solução (TUMELERO, BAHIA, 2018), e são propostas com perspectiva de melhoria a longo prazo.

As pesquisas de extensão podem ajudar esse tipo de escola a traçar melhores objetivos e metas para incluir as questões ambientais em seu cotidiano, podendo pensar em estratégias que introduzam ações capazes de impactar de forma mais expressiva a vida das pessoas.

Após a exposição dos indicadores, percebeu-se que os projetos dessas instituições caminham para acompanhar as mudanças sociais, sobretudo na esfera ambiental, o que é fundamental para que haja um desenvolvimento sustentável da sociedade.

\section{Conclusões}

Esse estudo demonstrou que a extensão universitária é uma poderosa aliada na busca por soluções para as lacunas da educação existentes com relação às questões ambientais. A união do ensino com a pesquisa e a

revista brasileira educação ambiental 
extensão é essencial para que as mais diversas temáticas deste eixo possam ser abordadas em conjunto aos variados tipos de pessoas, grupos e comunidades. Como dito no início, é apenas por meio da cooperação coletiva que os problemas, conflitos e falhas nas questões de sustentabilidade podem ser extintos e/ou amenizados. A extensão universitária, a partir dos seus projetos, é capaz de fazer com que a academia, representada pelos docentes, alunos, pesquisadores e extensionistas e a comunidade não acadêmica, conhecida como comunidade externa, possam, juntas, atuar em prol de um mundo mais sustentável objetivando, principalmente, viver com mais qualidade, ao mesmo tempo em que se protegem o meio ambiente, os seus recursos naturais e a qualidade de vida das pessoas.

A partir do questionário e da análise realizada neste artigo podemos compreender que as ações promovidas pelo projeto têm caminhado em busca da inclusão efetiva da pauta ambiental no ambiente educacional. Entretanto, ainda encontramos pontos falhos ao perguntarmos às escolas e a seus professores/pedagogos sobre algumas práticas. Os pontos onde o grau de concordância evidenciou-se baixo devem servir de reflexão para mudanças às futuras intervenções a serem realizadas.

O estudo evidenciou que um ideário frente à importância da sustentabilidade pode ser conseguido por meio da educação transformadora, com o auxílio da pesquisa e da extensão, incluindo iniciativas que privilegiam o acesso à informação e à transparência para a administração dos problemas ambientais e urbanos.

O presente estudo serviu como instrumento para que instituições se apropriem das aprendizagens e constatações efetivadas nesta pesquisa para estabelecer parcerias com as universidades, a fim de que as atividades extensionistas voltadas ao meio ambiente sejam incorporadas por ela. Ainda, com base nas respostas aqui apresentadas, contribui na consolidação de uma metodologia de análise de projeto de extensão, fornecendo mecanismos para a elaboração de ações visando alcançar ao desenvolvimento sustentável aqui defendido.

\section{Agradecimentos}

Gratidão ao Instituto Federal de Educação, Ciência e Tecnologia do Paraná e à Universidade do Vale do Itajaí (UNIVALI), pelo apoio pedagógico; à CAPES, pelo apoio financeiro; ao Instituto Crescer, à Vice-Reitoria de Extensão e Assuntos Comunitários da UNIVALI, ao Laboratório de Educação Ambiental (LEA) e ao Laboratório de Oceanografia Química e Poluição Marinha (LOQ), ambos da Escola do Mar Ciência e Tecnologia (EMCT) da Univali, aos bolsistas e voluntários do projeto Oceanos e aos professores e funcionários por tornarem possível o doutoramento da autora. 


\section{Referências}

CARMO, M.E. do; GUIZARDI, F. L. O conceito de vulnerabilidade e seus sentidos para as políticas públicas de saúde e assistência social. Cadernos de saúde Pública, v. 34, n.3, p.1-14. 2018.

COSTA, R.; SCHWANKE, C. Atitudes relacionadas ao Meio Ambiente: uma responsabilidade da Educação Ambiental. Educação ambiental em ação, v. 36, p. 1-7, jun./ago. 2011.

ESTEVES, A.M. et al. Adapting social impact assessment to address a project's human rights impacts and risks. In: Environmental Impact Assessment Review, vol. 67. pp. 73-87. 2017.

GADOTTI, M. Extensão Universitária: Para quê? 2017. Disponível em: $<$ https://www.paulofreire.org/images/pdfs/Extens\%C3\%A3o Universit\%C3\%A1r ia - Moacir Gadotti fevereiro 2017.pdf>. Acesso em: 29. out. 2019.

GONÇALVES, T.M. O Trabalho Interdisciplinar em Educação Ambiental: reflexões sobrea prática docente. Revista Brasileira de Educação Ambiental, v. 14, p.41-49, 2019.

INCROCCI, L.M.M.C; ANDRADE, T.N. (2018). O fortalecimento da extensão no campo científico: uma análise dos editais ProExt/MEC. Sociedade e Estado. v.33, n.1, p. 189-214. 10.1590/s0102-699220183301008.

JACOBI, P. Educação e meio ambiente: transformando as práticas. Revista Brasileira de Educação Ambiental, v.0, n.0, p. 28-35, 2004.

LEFF, E. Saber ambiental, sustentabilidade, racionalidade, complexidade, poder. Petrópolis: Vozes, 2009.

LORENZETTI, L. Estilos de pensamento em educação ambiental: uma análise de dissertações e teses. 2008. 407 f. Tese (Doutorado em Educação Científica e Tecnológica) - Programa de Pós-Graduação em Educação Científica e Tecnológica, Universidade Federal de Santa Catarina, Florianópolis, Disponível em: $\quad<$ https://repositorio.ufsc.br/xmlui/bitstream/handle/123456789/91657/ 258456. pdf? sequence $=1$ \&isAllowed $=\mathrm{y}>$. Acesso em 14 out. 2020.

LOUREIRO, C.F.B. Identidades da Educação Ambiental Brasileira. In: Educação ambiental transformadora. Brasília: Ministério do Meio Ambiente, p. 65-84 2004a.

LOUREIRO, C.F.B. Educar, participar e transformar em educação ambiental. Revista Brasileira de Educação Ambiental, v.0, n.0, p. 13-20, 2004b.

MATOS, A.D.; DANTAS, M.C. Fragilidades do Ensino da Educação Ambiental: Viés da customização. Revista Brasileira de Educação Ambiental, v.13, n.2, p.170-185, 2018.

POCHO, C.L. Avaliação de programas governamentais de educação ambiental: um caso de empresa estatal da área de energia. 2011. 419 f. Tese (Doutorado em Engenharia de Produção) - Programa de Pós-graduação em Engenharia 
de Produção, COPPE, Universidade Federal do Rio de Janeiro. Disponível em: $<$ http://producao.ufri.br/index.php/br/informacoess-academicas/teses-edissertacoes/doutorado/2011/253--218/file>. Acesso em 14 out. 2020.

SANTOS, B.M; MACCARI, G.R.; SEIXAS, A.C.M de. Ações da Extensão Universitária Voltadas à Educação Ambiental no Gerenciamento de Resíduos Sólidos. Brazilian Technology Symposium, ISSN 2447-8326. v.1. 2016.

SANTOS, B.S. La universidad en el siglo XXI. Para una reforma democrática y emancipatória de la universidad. La Paz: Plural Editores, 2007.

THIOLLENT, M. Construção do conhecimento e metodologia da extensão. $2002 . \quad$ Disponível em: <http://www.prac.ufpb.br/anais/lcbeu anais/anais/conferencias/construcao.pdf> . Acesso em: 29. out. 2019.

THIOLLENT. M. et al. Extensão universitária: conceitos, métodos e práticas. Rio de Janeiro: UFRJ, 2003.

TUMELERO, N.A.S; BAHIA, C.M. A Política Nacional de Educação ambiental e os saberes ambientais na construção do consumidor-cidadão. Revista Brasileira de Educação Ambiental, v. 13, n.1, p.124-139, 2018.

TRISTÃO, M. Uma abordagem filosófica da pesquisa em educação ambiental. Revista Brasileira de Educação, v. 18, n. 55, p. 847-860, 2013. 